\title{
DFG-1 Residue Controls Inhibitor Binding Mode and Affinity, Providing a Basis for Rational Design of Kinase Inhibitor Selectivity
}

\author{
Martin Schröder, Alex N. Bullock, Oleg Fedorov, Franz Bracher, Apirat Chaikuad,* and Stefan Knapp*
}

Cite This: J. Med. Chem. 2020, 63, 10224-10234

Read Online

ABSTRACT: Selectivity remains a challenge for ATP-mimetic kinase inhibitors, an issue that may be overcome by targeting unique residues or binding pockets. However, to date only few strategies have been developed. Here we identify that bulky residues located $\mathrm{N}$-terminal to the DFG motif (DFG-1) represent an opportunity for designing highly selective inhibitors with unexpected binding modes. We demonstrate that several diverse inhibitors exerted selective, noncanonical binding modes that exclusively target large hydrophobic DFG-1 residues present in many kinases including PIM, CK1, DAPK, and CLK. By use of the CLK family as a model, structural and biochemical data revealed that the DFG-1 valine controlled a noncanonical binding mode in CLK1, providing a rationale for selectivity over the closely related
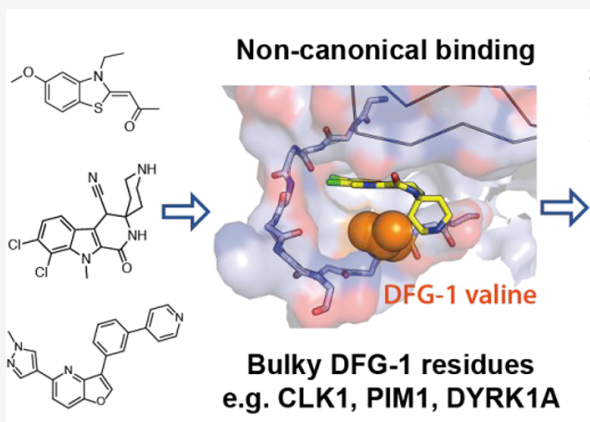

Bulky DFG-1 residues e.g. CLK1, PIM1, DYRK1A

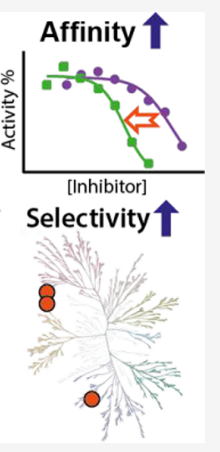
CLK3 which harbors a smaller DFG-1 alanine. Our data suggest that targeting the restricted back pocket in the small fraction of kinases that harbor bulky DFG-1 residues offers a versatile selectivity filter for inhibitor design.

\section{INTRODUCTION}

Protein kinases constitute one of the largest protein families in the human genome consisting of more than 500 members. ${ }^{1}$ Their tightly controlled catalytic activity plays a crucial role in the regulation of cellular signaling that orchestrates most cellular processes. ${ }^{2}$ Alteration of kinase functions due to mutations or overexpression often leads to pathogenesis in a large and diverse range of diseases. Thus, targeting protein kinases offers opportunities for the development of new medicines. Many kinases are therefore currently targeted in drug development programs which have resulted in 52 FDA approved small molecule drugs. ${ }^{3,4}$ However, most kinase inhibitors have been developed only for oncology applications. The development of highly selective inhibitors, which represents a tremendous challenge, would be required for nononcology applications.

The development of ATP competitive small molecule inhibitors for kinases has typically utilized two main binding modes. Type I inhibitors target the active state and are anchored by hydrogen bonds to the main chain atoms of the kinase hinge region that connect the two large kinase lobes. Type II inhibitors often also interact with the kinase hinge, but they target an inactive conformation characterized by reorientation of the tripeptide "DFG" motif (DFG-out) that creates a large pocket accessible to ATP mimetic inhibitors. ${ }^{5}$ Allosteric inhibitors (type III and type IV) have additionally been developed that are usually highly selective. However, the paucity of rational design strategies has resulted in comparably few potent inhibitors so far. ${ }^{5,6}$
Since protein kinases share in common the ATP binding pocket, achieving necessary selectivity for type I and type -II inhibitors is a challenging task. The discovery of the DFG-out conformation in the ABL1 crystal structure in complex with the first approved kinase drug imatinib (gleevec) was met with great interest as the structure suggested that targeting this conformational change may provide a rationale for the development of more selective kinase inhibitors. ${ }^{7}$ Indeed, the type II binding mode of imatinib is the main structural reason for its selectivity against the closely related SRC kinases. However, more comprehensive studies revealed that the DFGout conformation can be adopted by many kinases, providing not a rationale per se for selective inhibitor development. ${ }^{8}$

A few kinases have demonstrated other conformational changes that may lead to induced-fit pockets peripheral to the ATP binding site exploitable for the development of highly selectivity type I inhibitors. This is exemplified by SCH772984, which binds a unique P-loop pocket in ERK1/2. ${ }^{9}$ A rare glycine residue that allows flexibility in the hinge backbone has also been exploited for the development of skepinone-L and other p38 inhibitors. ${ }^{10-12}$ Furthermore, targeting a unique

Received: May 27, 2020

Published: August 12, 2020 
A

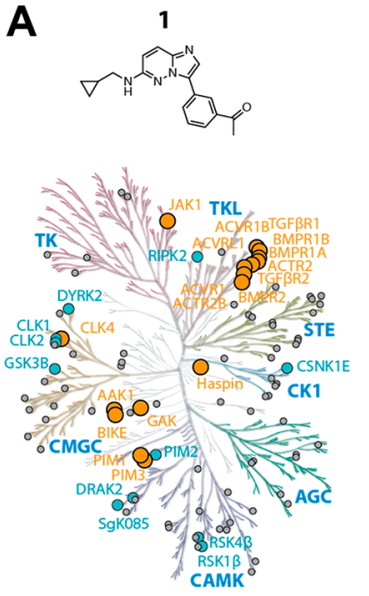

B
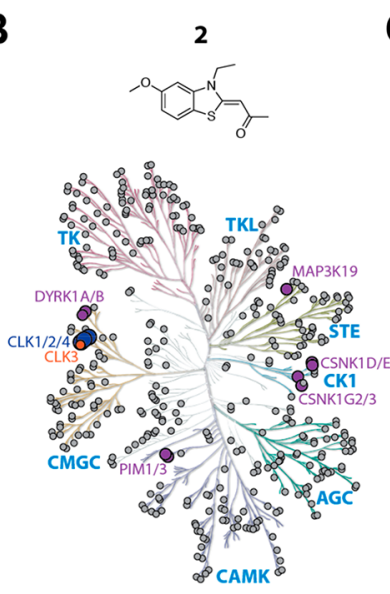

$\mathrm{Kd}:<100 \mathrm{nM}$ Kd:100nM-1 $\mu \mathrm{M}$

- Kd: $1-10 \mu \mathrm{M}$
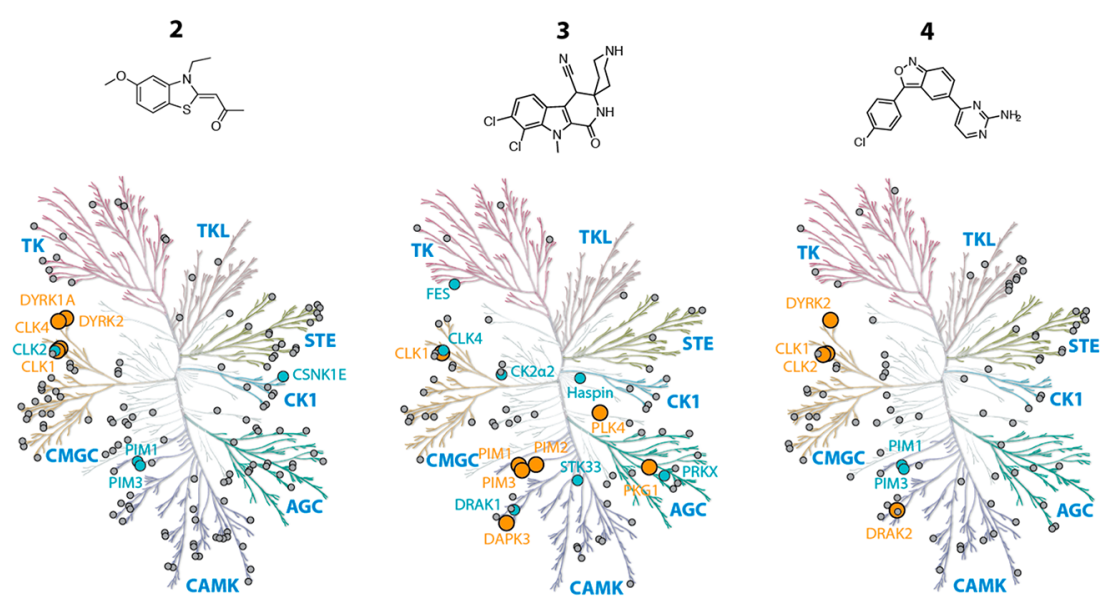

$O \Delta \mathrm{Tm}>6^{\circ} \mathrm{C} O \Delta \mathrm{Tm}>4^{\circ} \mathrm{C} O \Delta \mathrm{Tm}<4^{\circ} \mathrm{C}$

C
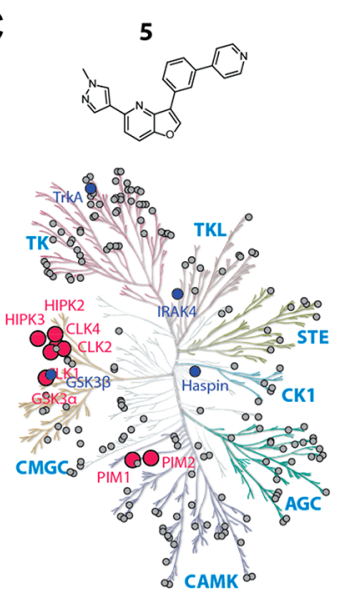

Kinase activity at $1 \mu \mathrm{M}$

$<25 \% \quad<50 \%$ o Tested
D

\begin{tabular}{|c|c|}
\hline \multicolumn{2}{|c}{$\mathbf{2}$} \\
\hline Kinase & IC50 (nM) \\
\hline CLK1 & 19 \\
\hline CLK2 & 95 \\
\hline CLK3 & 3000 \\
\hline CLK4 & 30 \\
\hline DYRK1A & 12 \\
\hline DYRK1B & 130 \\
\hline PIM1 & 130 \\
\hline PIM3 & 280 \\
\hline CSNK1D & 150 \\
\hline CSNK1E & 300 \\
\hline CSNK1G3 & 270 \\
\hline MAP3K19 & 290 \\
\hline
\end{tabular}

\begin{tabular}{|c|c|}
\hline \multicolumn{2}{|c|}{5} \\
\hline Kinase & IC50 (nM) \\
\hline CLK1 & 8 \\
\hline CLK2 & 20 \\
\hline CLK3 & $>3000$ \\
\hline CLK4 & 12 \\
\hline DYRK1A & 213 \\
\hline DYRK1B & 956 \\
\hline DYRK2 & 1309 \\
\hline HIPK1 & 187 \\
\hline HIPK2 & 29 \\
\hline HIPK3 & 159 \\
\hline
\end{tabular}

Figure 1. A common selectivity profile of diverse kinase inhibitors. Kinome-tree representation of the selectivity profiles of compounds $\mathbf{1}-\mathbf{5}$ measured by $(\mathrm{A})$ our melting temperature shift $\left(\Delta T_{\mathrm{m}}\right)$ assays or $(\mathrm{B}, \mathrm{C})$ published kinome-wide profiling data. ${ }^{24,27} \mathrm{Gray}$ dots indicate kinases in the assays, and colored dots demonstrate binding potencies as indicated in the schemes in each panel. (D) IC 50 values of 2 and $\mathbf{5}$ for selected kinases. $^{27,28}$

back pocket peripheral to the $\alpha \mathrm{C}$ and DFG motif offers a rationale for the high selectivity of cyclopropylethyl-substituted PI3K $\gamma$ inhibitors. ${ }^{13}$ In addition, covalent targeting cysteine residues offers an additional strategy for the development of highly selective irreversible inhibitors. ${ }^{14}$

Conserved residues lining the ATP binding site can also provide a determinant controlling protein kinase sensitivity to inhibitors. One key position in the kinase ATP site is the gatekeeper residue located at the beginning of the hinge region. Small residues at this position are present in a small proportion of kinases in the human kinome and open a hydrophobic back pocket that has been exploited in the development of many kinase inhibitors, including imatinib and erlotinib drugs. ${ }^{8,15-18}$ The important role of the gatekeeper is highlighted by mutations at this position which confer kinase resistance to cancer drugs that target the gatekeeper back pocket. ${ }^{19-21}$

Here we focused on a so far little explored residue position in the kinase active site that seems to be important for inhibitor selectivity and unexpected binding modes. This critical position is located N-terminal to the DFG motif (named here DFG-1, known also as $\mathrm{xDFG}$ ) and typically harbors a small residue. Nevertheless, larger hydrophobic amino acids, such as valine, isoleucine, and leucine, are observed in a few kinases. We observed that the presence of such bulky residues in this position favored unusual binding modes and often conferred selectivity for inhibitors of this group of kinases. In addition, we were able to show that amino acid substitution at the DFG-1 position could modulate inhibitor affinities and binding modes, providing a mechanism for subfamily selectivity within the highly conserved CLKs (Cdc2 like kinases) of which all members except CLK3 contain large hydrophobic residues in DFG-1. The presence of large DFG-1 residues in several potential drug targets such as PIM kinases, $\mathrm{CK} 1$, and DAPK3 offers a rationale for selective inhibitor development targeting this unusual residue variation.

\section{RESULTS}

Unexpected Similar Selectivity Pattern for Diverse Kinase Inhibitors. Selectivity of kinase inhibitors is typically achieved by moderate to high degrees of chemical decorations that target unique features within the target proteins. Analysis of melting temperature shift $\left(\Delta T_{\mathrm{m}}\right)$ assay data from multiple kinase systems identified a set of diverse inhibitors with limited decorations that exhibited markedly high selectivity (Figure 1). These included the imidazopyridazine K00135 first reported as a PIM1 inhibitor $^{22}$ (1), the benzothiazole TG003 reported as a 

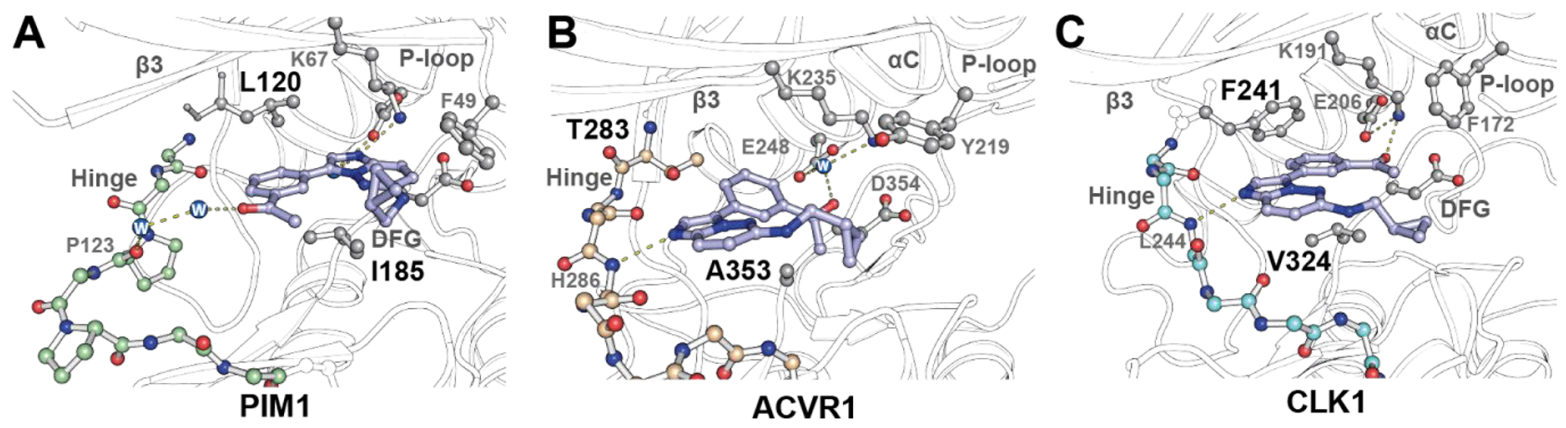

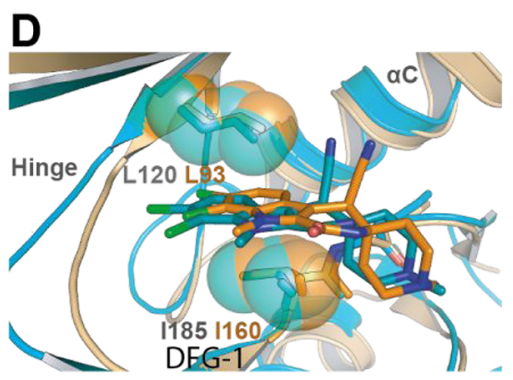

PIM1 DAPK3

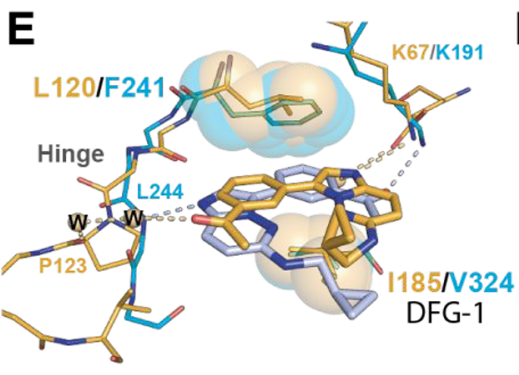

PIM1 CLK1
F

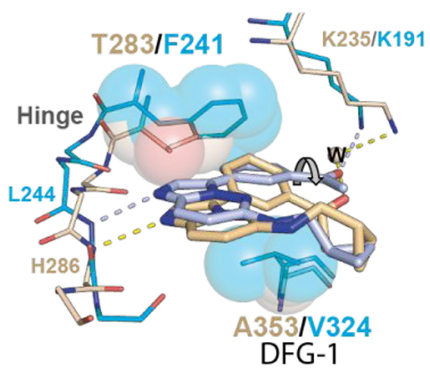

ACVR1 CLK1
G

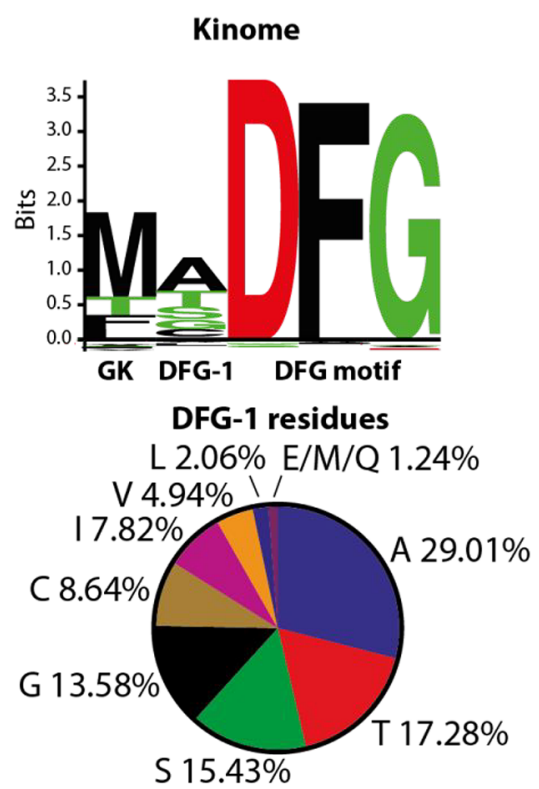

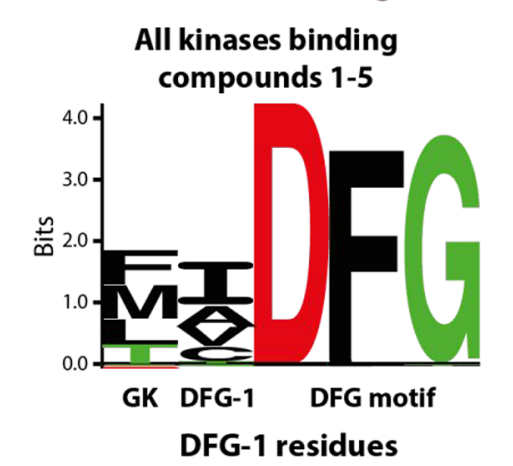

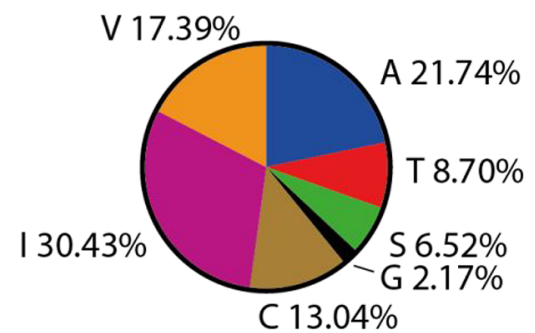

Figure 2. Alternative noncanonical binding modes of inhibitors stabilized by large hydrophobic DFG-1 residues. Cocrystal structures of 1 with PIM1 (A; PDB code 2c3i), ACVR1 (B; PDB code 4dym), and CLK1 (C; PDB code 6yta) reveal different binding modes of the inhibitor. (D) Altered binding modes of 2 in PIM1 (PDB code 3cxw) and DAPK3 (PDB code 3bhy). Superimposition between CLK1 and PIM1 (E) and between CLK1 and ACVR1 (F) reveals potential contribution of the gatekeeper and DFG-1 residues toward the different binding modes of 1 . (G) Distribution of amino acid compositions at the gatekeeper (GK) and DFG-1 positions across the human kinome (left) and among the cluster of kinases that are the targets of inhibitors $\mathbf{1 - 5}$ (right).

CLK inhibitor ${ }^{23,24}$ (2), the $\beta$-carboline $\mathrm{KH}$-CARB13 ${ }^{25}$ (3), and the benzisoxazole-pyrimidine-2-amine also reported to target PIM kinases ${ }^{26}$ (4) (Figure 1A,B and Supplementary Table 1). The furo[3,2-b]pyridine MU1210 (5) presented another example with even fewer off-targets and was recently developed as a chemical probe for CLK kinases (Figure 1C). ${ }^{27}$

Of particular note was a set of diverse kinases similarly targeted by these inhibitors. This was surprising considering the structural diversity of the inhibitors. Kinases that were potently inhibited belonged to diverse groups and families, including the CMGC group CDC-like kinases (CLKs) and dual specificity tyrosine-phosphorylation-regulated kinases
(DYRKs), the CAMK group PIM kinases, death-associated protein kinases (DAPKs), and DAP kinase-related apoptosisinducing protein kinases (DRAKs), and members of the casein kinase 1 family (CK1s). Our $\Delta T_{\mathrm{m}}$ binding data were corroborated by the reported nanomolar potencies of inhibitors $\mathbf{2}$ and $\mathbf{5}$ in enzyme kinetic assays (Figure 1D). ${ }^{27,28}$ Additional activities of $\mathbf{1}$ for some TKL kinases were also observed. Thus, the selectivity data suggested a potential common mechanism responsible for the unusual binding profile of these diverse inhibitors to kinases that share only weak sequence homology in their active sites. 
The DFG-1 Residue Modulates and Stabilizes Noncanonical Binding Modes. The kinase targets (CLK1, DYRK1A, haspin, PIM1, and DRAK2) that were inhibited by these diverse inhibitors share limited sequence identity (Supplementary Figure 1) which prompted us to investigate the structural mechanism of this reoccurring selectivity pattern.

First, we wanted to understand the unique activity of $\mathbf{1}$ for TKL family members, which represented an outlier in our selectivity comparison. The structure of $\mathbf{1}$ in complex with PIM1 published previously by our group revealed an unusual binding mode. ${ }^{22}$ The imidazopyridazine moiety of 1 was designed as a hinge binding group, yet the PIM1 complex revealed no canonical hinge interaction and instead the imidazopyridazine formed interactions within the back pocket of the ATP site including a hydrogen bond with the VIAK motif lysine (Figure $2 \mathrm{~A}$ ). In contrast, compound 1 reverted to a canonical binding mode in ACVR1 (Figure 2B), as well as CLK1 (Figure 2C), offering a structural rationale for the observed activities of this inhibitor. The noncanonical binding mode of 1 in PIM1 might be facilitated by the presence of a proline residue in the hinge region, which offer less possibilities for canonical hinge interaction for inhibitors, but instead enable the extended, curved hinge region suitable for an accommodation of the bulky acetophenone moiety. Unusual binding modes were also detected for the 1-oxo- $\beta$-carboline 3, an inhibitor with PIM1/3 and DAPK3 dual activity ${ }^{25}$ (Figure 2D). The inhibitor is expected to establish a canonical ATP mimetic binding mode through bidentate hydrogen bonds between the amide oxygen and nitrogen of the 1-oxo- $\beta$ carboline ring and the hinge as shown for inhibitors of this scaffold binding to RET and CDK2. ${ }^{29,30}$ In contrast, in the PIM1 and DAPK3 complexes, the inhibitors flipped $180^{\circ}$ to redirect the intended hinge binding moiety toward the back pocket, positioning the halogens for halogen bonds with a hinge backbone carbonyl group. Such large differences in binding modes are rarely seen for potent kinase inhibitors.

Further examination of the structures suggested that an additional key determinant for inhibitor binding was the combination of large hydrophobic residues at the DFG-1 and gatekeeper positions, which sandwiched aromatic ring systems in the inhibitors to stabilize the observed inverted binding modes. For instance, stabilization of the imidazopyridazine and acetophonone of $\mathbf{1}$ in the back pocket of PIM1 and CLK1, respectively, was achieved through contacts with the bulkier gatekeeper and DFG-1 residues, L120/I185 in PIM1 and F241/V324 in CLK1 (Figure 2E). The combination of large DFG-1 and gatekeeper residues also constrains the size of the back pocket binding site rendering it significantly narrower. This feature is absent in ACVR1, which has smaller residues at these positions (T283/A353) and thus larger space allowing more freedom for the inhibitor evident by an out-of-plane tilt of the inhibitor (Figure 2F). This binding mode led to the lack of contacts between 1 and ACVR1 back pocket, prompting us to postulate whether its canonical binding mode was primarily the result of the smaller DFG-1 alanine.

Our sequence analyses revealed that $84 \%$ of human kinases harbor a small hydrophilic residue in the DFG-1 position while the occurrence of large hydrophobic amino acids (leucine, valine, and isoleucine) is scarce (Figure $2 \mathrm{G}$ and Supplementary Table 2). In contrast, these large branched hydrophobic residues are common among the kinases that are the targets of inhibitors 1-5. As the kinases that contain large DFG-1 amino acids often share low sequence identities, this unusual DFG-1 residue variation may hold promise for designing selective inhibitors that are anchored in the back pocket between the gatekeeper and large hydrophobic DFG-1 residues. To investigate and establish such potential functions of the DFG-1 residue on kinase sensitivity to inhibitors, we used human CLKs as a model system and analyzed the contribution of these residues to ligand binding using site directed mutagenesis.

The Role of the DFG-1 in the CLK Subfamily for Inhibitor Binding. CLK kinases are key regulators of RNA splicing which is often deregulated in disease. ${ }^{31}$ All four members of the human CLK family share highly conserved structural topology. ${ }^{32}$ However, there are some amino acid variations within their ATP binding pockets. While most are peripheral and located in solvent expose regions, the difference at the DFG-1 position is of particular significance (Figure $3 \mathrm{~A}$ ). CLK1/2/4 harbor a DFG-1 valine residue, whereas an alanine is found at this position in CLK3. The presence of this alanine coincided with the lack of significant binding of inhibitor 1-5 for CLK3 (Figure 1), prompting us to speculate that the preferred binding of these inhibitors to CLK1/2/4 was conferred by the substitution of a DFG-1 valine. To test this hypothesis, we generated two mutants, CLK1 V324A (a "CLK3-like" CLK1) and CLK3 A319V (a "CLK1-like" CLK3), and assessed their binding to 18 different CLK inhibitors we had available in our laboratory using thermal shift assays. Comparison between the melting temperature shifts $\left(\Delta T_{\mathrm{m}}\right)$ of the mutant and wild type proteins demonstrated negative and positive $\Delta T_{\mathrm{m}}$ differences $\left(\Delta \Delta T_{\mathrm{m}}\right)$ of $\sim 4{ }^{\circ} \mathrm{C}$ for the CLK1 and CLK3 pairs, respectively. This was consistent with our hypothesis, suggesting a loss in inhibitor binding for the CLK1 mutant and a gain in the CLK3 mutant (Figure 3B and Supplementary Table 3). The $\Delta T_{\mathrm{m}}$ results were in agreement with the approximately 3 - to 32 -fold changes in inhibitory constants $\left(K_{\mathrm{i}}\right)$ for 2 and 3 measured in live cells using nanoBRET $^{33,34}$ and enzyme kinetic assays ${ }^{35,36}$ for CLK1 and CLK3, respectively (Figure 3C). The loss of inhibitor binding affinities against the CLK1 mutant was apparent also for other inhibitors tested, except staurosporine (6), with more profound changes in $K_{\mathrm{i}}$ of approximately 9- to 109-fold observed for KH-CB19 (7) ${ }^{37}$ and GW807982X (8) $)^{38,39}$ (Figure 3D and Supplementary Table 4). These results suggested therefore that the smaller DFG-1 alanine is likely responsible for the loss of inhibitor binding in CLK3.

DFG-1 Residue Alters the Back Pocket and Binding Modes. To study the influence of the DFG-1 residue on inhibitor binding to CLK1 and CLK3, we selected compounds $\mathbf{2}$ and $\mathbf{3}$ for more detailed structural studies to understand their distinct binding affinities for these kinases. We determined crystal structures for the inhibitor complexes of both the wild type and DFG-1 mutant kinases. Although the binding mode of 2 was not affected in all four proteins, subtle differences within the back pocket were evident. Most notable were differences in the interactions between the benzothiazole moiety and the DFG-1 residues (Figure 4A-D). A short distance of $\sim 3.9 \AA$ in CLK1 indicated van der Waals contacts between the inhibitor with the DFG-1 Val324, which were absent in wild type CLK3 due to its smaller DFG-1 alanine (A319). Interestingly, the DFG-1 mutations led to a reverse scenario in which the van der Waals contacts were likely diminished in the CLK1 V324A mutant but could likely be introduced in the CLK3 A319V mutant. The loss of interaction with the DFG-1 side chain likely explains the lower potency of 

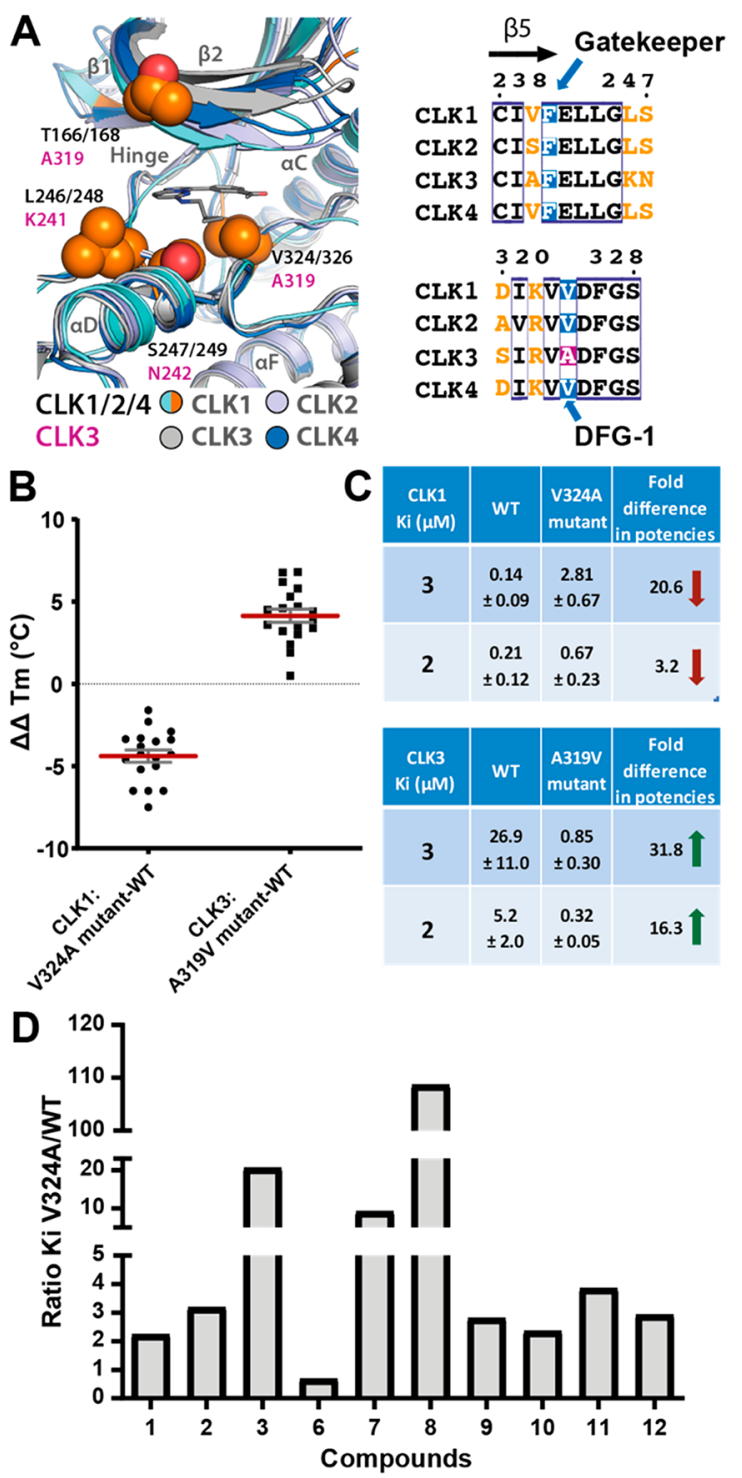

Figure 3. Effects of DFG-1 amino acid composition on inhibitor binding in CLK1 and CLK3. (A) Comparative structural and sequence analyses reveal the difference within the ATP binding pockets at the DFG-1 position in the CLK subfamily, noted by a valine to alanine substitution in CLK3 (CLK1, PDB code 6yta; CLK2, PDB code 3nr9; CLK3, PDB code 6ytw; CLK4, PDB code: 6 fyv $^{40}$ ). (B) Plots of melting temperature shifts $\left(\Delta T_{\mathrm{m}}\right)$ differences $\left(\Delta \Delta T_{\mathrm{m}}\right)$ between the mutant and wild type for 18 test compounds reveal negative and positive values for the CLK1 and CLK3 pairs, respectively (see Supplementary Table 3 for $\Delta T_{\mathrm{m}}$ for all inhibitors). (C) Average inhibitory constants $\left(K_{\mathrm{i}}\right)$ for $\mathbf{2}$ and 3 measured by NanoBRET (biological duplicates) and Omnia assays (triplicates) for CLK1 and CLK3, respectively. (D) Ratio of $K_{\mathrm{i}}$ between the CLK1 V324A mutant and wild type (WT) demonstrates reduction of binding potencies of most inhibitors $\left(9, \mathrm{~K} 00518 ; 10, \mathrm{~T}^{-C L K}{ }^{41} \mathbf{1 1}\right.$, $\mathrm{KuWal} 151 ;{ }^{42}$ 12, $\left.\mathrm{FC} 162^{43}\right)$.

2 for CLK3 and the CLK1 V324A mutant. In addition, further examination of the structures revealed the distinct nature of the inhibitor binding cavities; a more compact pocket $\left(\sim 136 \AA^{3}\right)$ was observed in wild type CLK1 and the CLK3 mutant harboring DFG-1 valine, whereas a relatively large pocket $\left(\sim 217 \AA^{3}\right)$ was present in wild type CLK3 and the CLK1 mutant with DFG-1 alanine (Figure 4E). Isothermal calorimetry (ITC) measurements revealed minor entropic contribution, yet favorable, for the binding of 2 in both wild type CLK1 and CLK3, suggesting no significant induced change in their pocket environment. A superior enthalpy contribution observed for the 2-CLK1 interaction was expected from the improved contacts within the restricted cavity, feasibly explaining the tighter binding of the inhibitor in this kinase (Figure 4F).

Surprisingly, the cocrystal structures revealed two distinct binding modes of 3 in CLK1 and CLK3 (Figure 5A,B). In the CLK1 complex, the $\beta$-carboline inhibitor formed an uncommon halogen bond with the hinge, the binding mode resembling that observed in PIM1 and DAPK $3 .{ }^{25}$ In contrast, the inhibitor flipped in CLK3 to its canonical binding mode interacting with the hinge and the solvent-exposed region. This pronounced contrast in the binding modes presumably reflected the different abilities for their back pocket to accommodate the inhibitor. The larger V324 potentially restricted the binding cavity and assisted stabilization of the $\beta$-carboline in CLK1 through van der Waals interactions, a scenario that was likely absent in the larger pocket of CLK3 with its smaller DFG-1 A319. Such a potential role for the DFG-1 residue was further supported by the CLK3 mutant structure, in which the narrowing of the back pocket by the A319V substitution led to an inverted binding mode which once again resembled that observed in wild-type CLK1 (Figure 5C). The potential DFG-1-assisted stabilization of the $\beta$ carboline in CLK1 and A319V CLK3, as well as PIM1 and DAPK3, also enabled positioning of the nitrile group in the vicinity to the catalytic lysine (K191 and K186 in CLK1 and CLK3, respectively), which may lead to polar contacts explaining more favorable binding and the affinity gains in these kinases. Overall, these results established an important role for the DFG-1 residue in determining the nature of the pockets controlling kinase sensitivity. In particular, bulkier amino acids at this position may assist stabilization of highaffinity noncanonical binding mode of inhibitors, providing a basis for their selectivity.

Targeting the DFG-1 Residue Determines Selectivity of CLK1/2/4 over CLK3. Our characterization showed that the restricted back pocket and the larger DFG-1 residue provided a mechanism for the high potencies of $\mathbf{2}$ and 3 for CLK1 and selectivity over CLK3. To investigate whether other inhibitors developed for this kinase family might share similar binding behavior, we profiled seven inhibitors reported previously to bind CLK1 using $\Delta T_{\mathrm{m}}$ assays (Figure 6A). Interestingly, all screened compounds exhibited similar behavior to 2 and 3 with binding preference for CLK1/2/4 over CLK3. Analyses of the crystal structure of CLK1 with GW807982X (8) and ETH1610 (13) ${ }^{44}$ revealed that these inhibitors exhibited similar binding mechanisms by tightly interacting with DFG-1 V324 (Figure 6B). Again, the CLK1 $\mathrm{V} 324 \mathrm{~A}$ mutant showed reduced inhibitor binding potency in contrast to an increase in affinities for the CLK3 A319V mutant (Figure 6B). Overall, these results demonstrate that many diverse scaffolds can exhibit such atypical binding mechanisms by targeting the bulkier DFG- 1 valine residue and achieve high potency for CLK1/2/4 with selectivity over CLK3.

\section{DISCUSSION AND CONCLUSION}

The rational design of kinase inhibitor with high selectivity is a challenging task. Although unique pockets peripheral to the ATP binding site may offer an opportunity to overcome this 
A

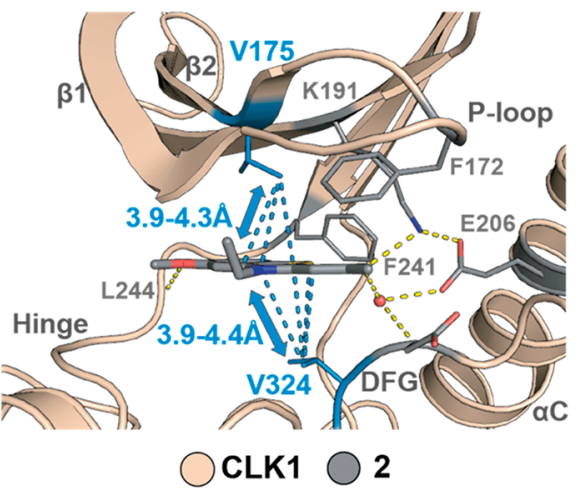

C

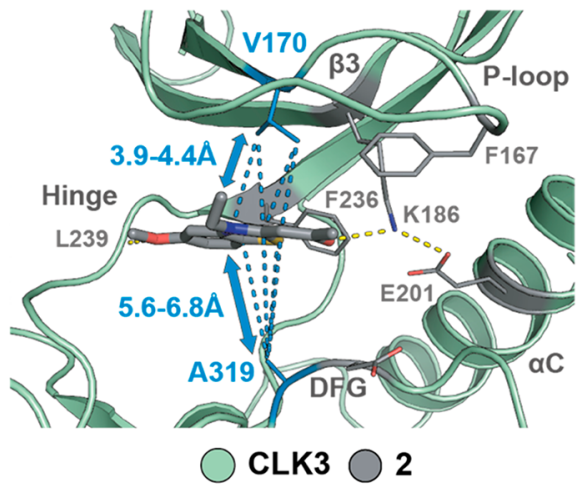

E

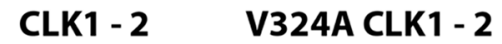

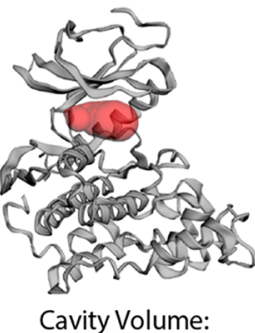

$136 \AA^{3}$

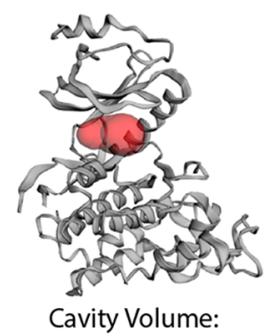

$217 \AA^{3}$

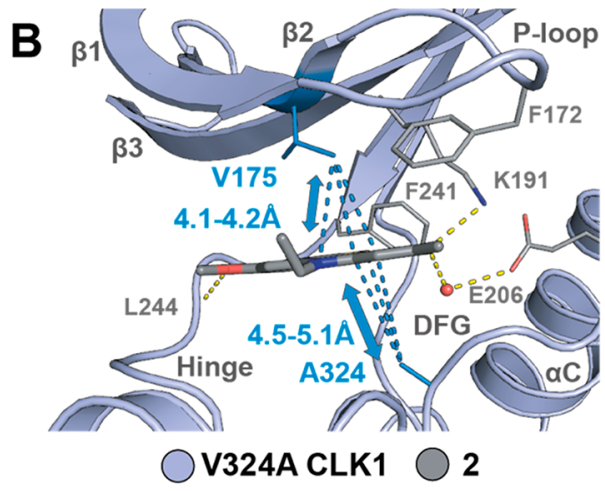

D

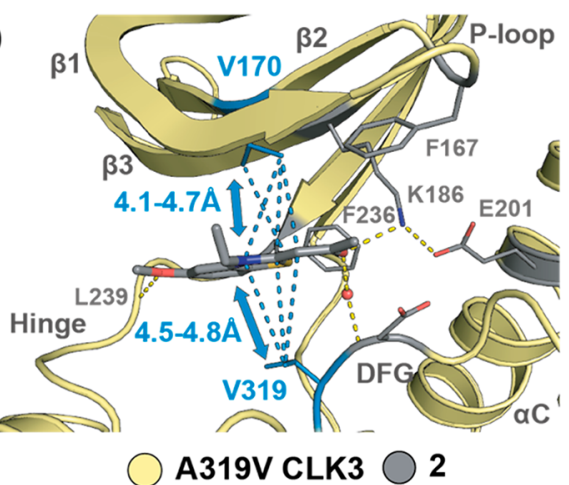

CLK3 - 2

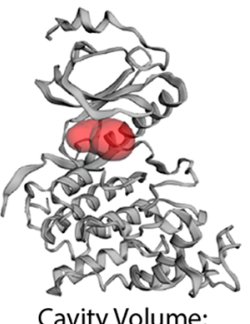

$217 \AA^{3}$
A319V CLK3 - 2

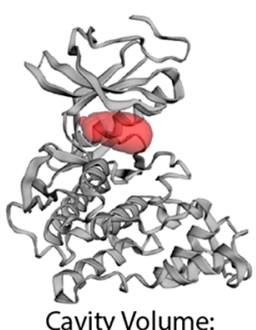

$136 \AA^{3}$
$\mathbf{F}$

CLK1- 2

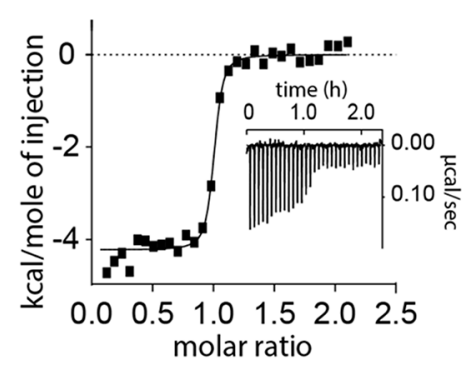

CLK3 - 2

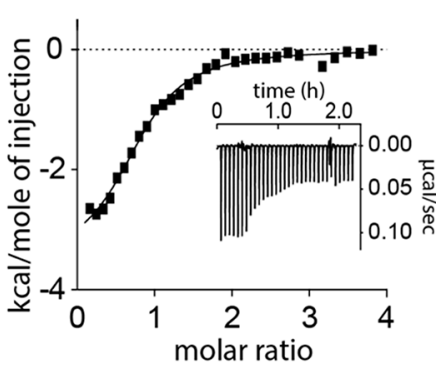

\begin{tabular}{|c|c|c|}
\hline & CLK1 -2 & CLK3 -2 \\
\hline $\mathrm{Kd}(\mu \mathrm{M})$ & $0.075 \pm$ & 7.78 \\
& 0.04 & \pm 0.90 \\
$\mathrm{n}$ & 1.2 & 0.95 \\
& \pm 0.1 & \pm 0.1 \\
\hline $\begin{array}{c}\Delta \mathrm{H} \\
(\mathrm{kcal} / \mathrm{mol})\end{array}$ & -7.96 & -3.06 \\
\hline $\begin{array}{c}\mathrm{T} \Delta \mathrm{S} \\
(\mathrm{kcal} / \mathrm{mol})\end{array}$ & 2.25 & \pm 0.4 \\
\hline $\begin{array}{c}\Delta \mathrm{G} \\
(\mathrm{kcal} / \mathrm{mol})\end{array}$ & -10.21 & $\begin{array}{c}-6.74 \\
\pm 0.03\end{array}$ \\
\hline \multicolumn{2}{|c}{} \\
\hline \multicolumn{2}{|c|}{}
\end{tabular}

Figure 4. Different binding mechanisms of 2 in CLK1 and CLK3. (A-D) The crystal structures of the complexes of 2 with wild type (CLK1, PDB code 6yte; CLK3, PDB code 6ytw) and mutant CLK1 and CLK3 (V324A CLK1, PDB code 6ytd; A319V CLK3, PDB code 6yty) demonstrate similar binding modes of the inhibitor but different atomic distances between the $\beta 2$ valine (V175 and V170 in CLK1 and CLK3, respectively) and the DFG-1 residues, suggesting different van der Waals contacts. Note the estimated coordinate errors by Luzzati plot for these structures are 0.203-0.261 Å. (E) Pocket cavities of wild type and mutant CLK1 and CLK3 calculated for the 2-complexed structures. (F) Thermodynamics of the inhibitor binding in CLK1 and CLK3 measured by ITC. Shown are integrated heat of binding, the raw isotherms (inset), and the average $K_{\mathrm{D}}$ values and thermodynamic parameters.

issue, ${ }^{9,10,13}$ the discovery of structural features present only in few kinases is rarely reported. Targeting small gatekeeper residues that are present in a small proportion of kinases in the human kinome is now widely used and has led to selective inhibitors in particular for receptor tyrosine kinases ${ }^{15-17}$ as well as members of the TGF $\beta$ receptor family. ${ }^{45}$ Here we reported another alternative strategy for selective inhibitor design that makes use of bulky hydrophobic residues at the DFG-1 position present in only $15 \%$ of all human kinases. These kinases are present in most families of the human 
A

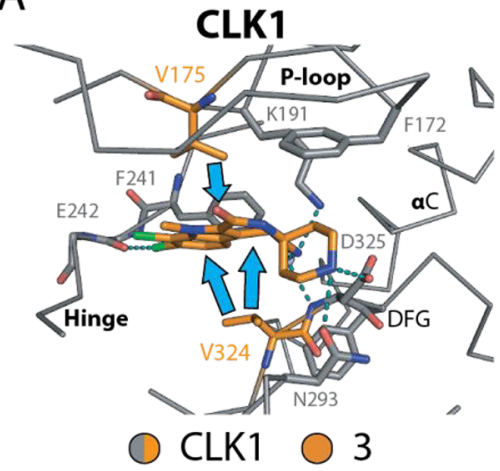

B

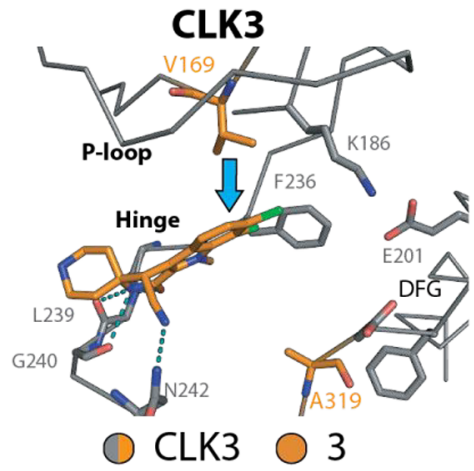

Hinge

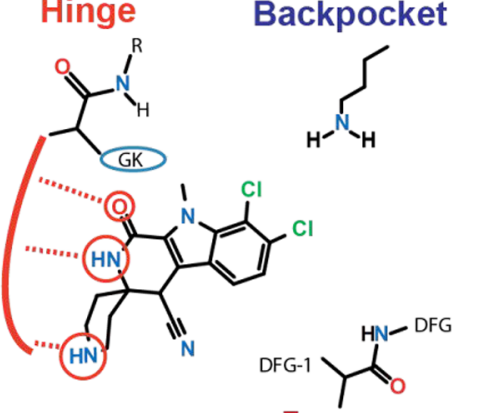

Affinity $\downarrow$

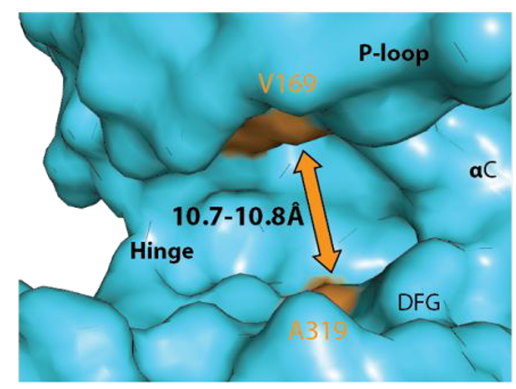

C
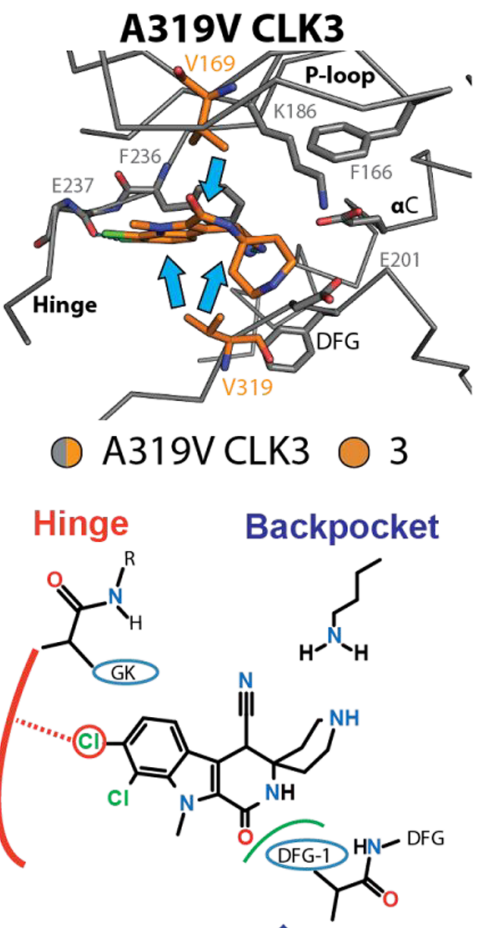

Affinity

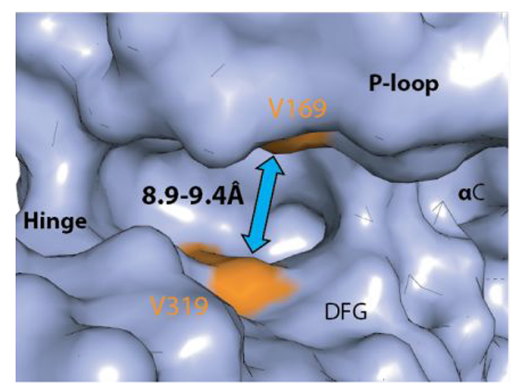

Figure 5. Noncanonical and canonical binding modes of 3 within the back pocket of CLK1 and CLK3. Comparison of the binding modes of 3 within CLK1 wild type (A; 6ytg), CLK3 wild type (B; 6yu1), and A319V CLK3 mutant (C; 6z2v). Detailed interactions of the inhibitor within the kinases are shown in the top and middle panels, while the lower panels illustrate the different pocket cavities among these kinases. Blue arrows indicate potential van der Waals contacts, while dashed lines indicate hydrogen bonds.

kinome, and the low sequence conservation among these unrelated kinases with bulky DFG-1 can be exploited to achieve exclusive selectivity for a kinase target. We showed in this study that in the case of the CLK family the CLK 3 isoform is often spared by inhibitors that make contact with the DFG-1 residue. The strategy is particularly attractive as inhibitors binding to the back pocket of kinases that harbor large DFG-1 residues often have unusual binding modes, such as compound 3, or rely less on classical hinge interactions, such as compound 2. The unexpected binding behavior of CLK family kinases has been reported previously, ${ }^{40,46}$ but the structural rationale has remained unknown. Here we demonstrated the role of the DFG-1 residue by site directed mutagenesis as well as structural insights, revealing that large residues at this DFG-1 position control the high-affinity, noncanonical binding modes that target the back pocket. This likely provides a mechanism for the enhanced selectivity of most CLK1/2/4 inhibitors over closely related CLK3. It is interesting to note that the most selective inhibitors including the casein kinase $2 \alpha 1$ (CK2 $\alpha 1)$ inhibitor GO289, ${ }^{47}$ the dual PIM/DAPK3 inhibitor HS56, ${ }^{48}$ the selective DAPK3 inhibitors HS94 and HS184, ${ }^{48}$ and the
CLK inhibitor MU1210 27 do not significantly interact with the hinge backbone but rather engage contacts at the back pocket particularly with the DFG-1 residue. Such binding modes have also been noted by the KLIFS database. ${ }^{49}$ Strong hinge binding motifs may also result in canonical hinge binding modes as observed for compound 1 binding to ACVR1 and CLK1 resulting in less favorable selectivity profiles. Thus, large and bulky DFG-1 residues offer a general anchor point for inhibitor design independent of the commonly used ATP mimetic hinge region. The improved activities and selectivity profiles of the selected inhibitors demonstrated here suggest therefore that targeting large DFG-1 residues and unusual back pockets presents an attractive general strategy for the design of new chemical libraries for many kinases.

\section{EXPERIMENTAL SECTION}

Compounds. All compounds used in this study were obtained commercially or from sources listed in Supplementary Table 3. Purity of all compounds is $>95 \%$ as confirmed by the sources.

Protein Expression, Purification, and Structure Determination. Recombinant wild type CLK1 (H148-I484) and CLK3 
A

\begin{tabular}{|c|c|c|c|c|c|c|c|c|c|}
\hline Kinase & Gatekeeper & DFG-1 & $\begin{array}{c}\Delta \mathrm{Tm} \\
2 \\
\left({ }^{\circ} \mathrm{C}\right) \\
\end{array}$ & $\begin{array}{c}\Delta \mathrm{Tm} \\
\mathbf{3} \\
\left({ }^{\circ} \mathrm{C}\right)\end{array}$ & $\begin{array}{c}\Delta \mathrm{Tm} \\
8 \\
\left({ }^{\circ} \mathrm{C}\right) \\
\end{array}$ & $\begin{array}{c}\Delta \mathrm{Tm} \\
11 \\
\left({ }^{\circ} \mathrm{C}\right) \\
\end{array}$ & $\begin{array}{c}\Delta \mathrm{Tm} \\
13 \\
\left({ }^{\circ} \mathrm{C}\right)\end{array}$ & $\begin{array}{c}\Delta \mathrm{Tm} \\
14 \\
\left({ }^{\circ} \mathrm{C}\right)\end{array}$ & $\begin{array}{c}\Delta \mathrm{Tm} \\
15 \\
\left({ }^{\circ} \mathrm{C}\right)\end{array}$ \\
\hline CLK1 & $\mathbf{F}$ & v & 10.2 & 8.0 & 9.0 & 9.8 & 10.3 & 12.3 & 16.5 \\
\hline CLK2 & $\mathbf{F}$ & v & 6.5 & 3.5 & 8.4 & 4.9 & 7.0 & 8.3 & 12.0 \\
\hline CLK3 & $\mathbf{F}$ & A & 3.0 & 1.4 & 2.0 & 2.3 & 3.4 & 4.8 & 5.8 \\
\hline CLK4 & $F$ & v & 9.6 & 9.2 & 9.0 & 10.1 & 9.6 & N/A & 14.3 \\
\hline
\end{tabular}

B

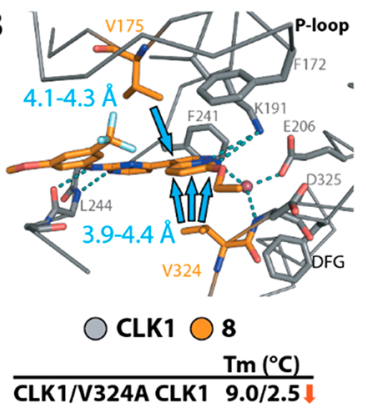

CLK3/A319V CLK3 $2.0 / 5.5$

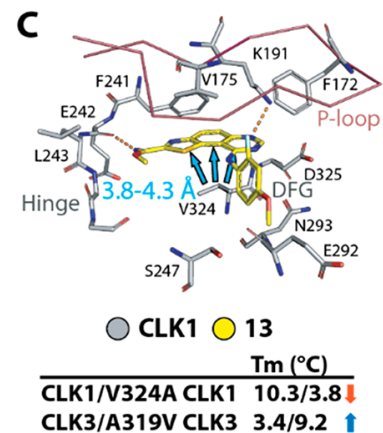

Figure 6. Unusual binding mechanism of targeting the DFG-1 residue for subfamily selectivity is shared by several CLK inhibitors. (A) $\Delta T_{\mathrm{m}}$ for reported CLK inhibitors demonstrates selectivity over CLK3 (EHT1610 (13), ${ }^{44}$ VN412 (14), ${ }^{27}$ GW779439X $\left.(15)^{38}\right)$. The crystal structures of CLK1 with $8(\mathrm{~B} ; 6 \mathrm{zln})$ and 13 (C; 6yti) reveal that the binding modes of these inhibitors likely depend on van der Waals interactions (blue arrows) with DFG-1 V324 in the back pocket. Lower panels show $\Delta T_{\mathrm{m}}$ for CLK1 and CLK3 wild type and mutants, indicating the changes of inhibitor binding affinities that correspond to the different DFG-1 amino acids.

(R134-T484) and their mutants, which were generated by PCR-based site directed mutagenesis, were expressed in E. coli and purified using the procedure described previously. ${ }^{32}$ Crystallization of the apo kinases and their inhibitor complexes was performed using sitting vapor diffusion method at $4{ }^{\circ} \mathrm{C}$ and the conditions listed in Supplementary Table 5. Soaking was performed with $5 \mathrm{mM}$ inhibitors.

For ACVR1, the kinase domain of ACVR1 R206H (residues 201499) was subcloned into the vector pFB-LIC-Bse for baculoviral expression in Sf9 cells at a density of $2 \times 10^{6} / \mathrm{mL}$ grown at $27^{\circ} \mathrm{C}$, shaking at $110 \mathrm{rpm}$, At $48 \mathrm{~h}$ after infection cells were harvested and resuspended in $50 \mathrm{mM}$ HEPES, $\mathrm{pH} 7.5,500 \mathrm{mM} \mathrm{NaCl}, 5 \mathrm{mM}$ imidazole, $5 \%$ glycerol, $0.1 \mathrm{mM}$ TCEP supplemented with protease inhibitor set V (Calbiochem). Cells were lysed using a C5 high pressure homogenizer (Emulsiflex), then centrifuged at $21000 \mathrm{rpm}$ and $4{ }^{\circ} \mathrm{C}$ for $1 \mathrm{~h}$, and the supernatant was recovered for purification. The protein was purified initially by Ni-affinity chromatography before being treated with TEV protease to remove the His tag. Further purification was achieved by size exclusion chromatography using a S200 HiLoad 16/60 Superdex column. The cleaved ACVR1 protein was finally passed through another $\mathrm{Ni}$-affinity chromatography column before being buffered for storage in $50 \mathrm{mM}$ HEPES, $\mathrm{pH} 7.5$, $300 \mathrm{mM} \mathrm{NaCl}, 10 \mathrm{mM} \mathrm{DTT}$, and $10 \mathrm{mM}$ L-arginine, $10 \mathrm{mM} \mathrm{L}$ glutamate at a concentration of $10 \mathrm{mg} / \mathrm{mL}$. Crystals of ACVR1 $\mathrm{R} 206 \mathrm{H}$ with $\mathrm{K} 00135$ were grown at $20{ }^{\circ} \mathrm{C}$ in a sitting drop by mixing $75 \mathrm{~nL}$ of protein solution with $75 \mathrm{~nL}$ of a reservoir solution containing 1.6 $\mathrm{M} \mathrm{MgSO}_{4}$ and 0.1 M MES, pH 6.5.

All crystals were cryoprotected using $25 \%$ ethylene glycol, and diffraction data were collected at BESSY, Diamond Light Source, and SLS. Data were processed using iMosflm ${ }^{50}$ or $\mathrm{XDS}^{51}$ and subsequently scaled using aimless. ${ }^{22}$ Molecular replacement was performed using Phaser ${ }^{53}$ and the coordinates of CLK1 (PDB code 1z57), ${ }^{32}$ CLK3 (PDB code 2eu9), ${ }^{32}$ and ACVR1 (PDB code 3h9r). ${ }^{54}$ Model rebuilding alternating with structure refinement was performed in COOT $^{55}$ and REFMAC, ${ }^{56}$ respectively. Geometric correctness was validated using Molprobity. ${ }^{57}$ Solvent accessible area was calculated using CASTp $^{58}$ with a $2 \AA$ cutoff radius. Data collection and refinement statistics are summarized in Supplementary Table 5, and the omitted electron density maps for the bound ligands are shown in Supplementary Figure 2.

Sequence Alignment Analyses. Alignment of the kinase domain sequences of 536 kinases was performed using Clustal Omega. ${ }^{59}$ Relative occurrence of amino acids was analyzed using the $P$-weighted Kullback-Leibler method from which the plots were generated using SeqtoLogo version 2.0. ${ }^{60}$

Melting Temperature Shift Assays. Recombinant protein at 2 $\mu \mathrm{M}$ in $10 \mathrm{mM}$ HEPES, $\mathrm{pH} 7.5$, and $500 \mathrm{mM} \mathrm{NaCl}$ was mixed with 10 $\mu \mathrm{M}$ inhibitors. The reaction was incubated at room temperature for $10 \mathrm{~min}$. SyPRO orange (Invitrogen) was added at 1:1000 dilution, and the fluorescence signals corresponding to temperature-dependent protein unfolding were measured using a real-time PCR Mx3005p machine (Stratagene). Melting temperature shifts were calculated using the previously described method. ${ }^{61}$

Omnia Kinase Assay. Recombinant CLK3 wild type and A319V mutant at $60 \mathrm{nM}$ in reaction buffer containing $20 \mathrm{mM}$ Tris, $\mathrm{pH} 7.5$, $25 \mathrm{mM} \mathrm{MgCl} 2,10 \%$ glycerol were mixed with $40 \mu \mathrm{M}$ Sox-modified substrate peptide (Ac-ERMRPRKRQGSVdP(Sox)G-NH $\mathrm{H}_{2}$ ). Compounds in a serial dilution were added to the reaction mixture, and after incubation for $5 \mathrm{~min}$ at $25{ }^{\circ} \mathrm{C}$ substrate phosphorylation was initiated by addition of $0.1 \mathrm{mM}$ ATP. The kinase activity was monitored by an increase in fluorescence signal using a Tecan Spark or BMG Clariostar instrument with $360 \mathrm{~nm}$ excitation and $460 \mathrm{~nm}$ emission wavelengths. Concentration-dependent changes in initial velocities were fitted using a dose-response equation in Prism, and the measured $\mathrm{IC}_{50}$ values were used for the inhibitory constant $\left(K_{\mathrm{i}}\right)$ calculation using the Cheng-Prussof equation and the ATP $K_{\mathrm{m}}$ values of $58.9 \pm 20.3$ and $8.6 \pm 4.2 \mu \mathrm{M}$ calculated from triplicate for the wild type and mutant, respectively.

NanoBRET Assays. Full-length CLK1 wild type and V324A mutant were subcloned into $\mathrm{pFC} 32 \mathrm{~K}$ (promega) with $\mathrm{N}$ - or $\mathrm{C}$ terminal NanoLuc fusion, respectively. The plasmids were transfected into HEK 293T cells, which were cultured for $20 \mathrm{~h}$ at $37^{\circ} \mathrm{C}$ and $5 \%$ $\mathrm{CO}_{2}$ to allow for protein expression. The NanoBRET assays were performed as described previously. ${ }^{62}$ In brief, after incubation cells were harvested and resuspended in Opti-MEM media and subsequently mixed and incubated with inhibitors and $1 \mu \mathrm{M}$ Tracer K5 (Promega) for $2 \mathrm{~h}$. The mixture of NanoBRET Nano-Glo substrate and extracellular NanoLuc inhibitor (Promega) was added immediately prior to BRET luminescence measurements $(450 \mathrm{~nm}$ for donor emission and $610 \mathrm{~nm}$ for acceptor emission) using a PHERAstar FSX plate reader (BMG Labtech). Milli-BRET units $(\mathrm{mBU})$ calculated as a ratio of BRET signal to the overall luciferase signal were fitted using a dose-response equation in Prism. The obtained $\mathrm{IC}_{50}$ values were used for $K_{\mathrm{i}}$ calculation using a Tracer K5 $K_{\mathrm{d}}$ of 0.254 and $0.222 \mu \mathrm{M}$ for the wild type and V324A mutant, respectively.

Isothermal Titration Calorimetry. ITC measurements were performed in a NanoITC (TA Instruments) at $15{ }^{\circ} \mathrm{C}$ in a buffer containing $50 \mathrm{mM}$ HEPES, $\mathrm{pH} 7.5,500 \mathrm{mM} \mathrm{NaCl}, 50 \mathrm{mM}$ arginine, $50 \mathrm{mM}$ glutamate, $0.5 \mathrm{mM}$ TCEP, and $5 \%$ glycerol. The kinase at 130 $\mu \mathrm{M}$ was injected into the reaction cell, which contained inhibitor 2 at $15 \mu \mathrm{M}$. The integrated heat of titration was calculated and fitted to an independent binding model according to the manufacturer's protocol. The thermodynamic parameters, dissociation constants $\left(K_{\mathrm{D}}\right)$, and stoichiometry $(n)$ were calculated.

\section{ASSOCIATED CONTENT}

\section{S1 Supporting Information}

The Supporting Information is available free of charge at https://pubs.acs.org/doi/10.1021/acs.jmedchem.0c00898.

Figures and tables (PDF)

Molecular formula strings and some data (CSV) 


\section{Accession Codes}

The coordinates and structure factors of all complexes have been deposited to the Protein Data Bank under accession codes 6yta, 6yte, 6ytd, 6ytw, 6yty, 6yu 1, 6z2v, 6zln, 6yti, 4dym, and 3 nr9.

\section{AUTHOR INFORMATION}

\section{Corresponding Authors}

Apirat Chaikuad - Institute of Pharmaceutical Chemistry and Structural Genomics Consortium, Buchmann Institute for Molecular Life Sciences (BMLS), Goethe-University Frankfurt, 60438 Frankfurt, Germany; 이이. orcido000-0003-11202209; Email: chaikuad@pharmchem.uni-frankfurt.de

Stefan Knapp - Institute of Pharmaceutical Chemistry and Structural Genomics Consortium, Buchmann Institute for Molecular Life Sciences (BMLS), Goethe-University Frankfurt, 60438 Frankfurt, Germany; German Translational Cancer Network (DKTK), 60438 Frankfurt, Germany; 이이.org/ 0000-0001-5995-6494; Email: knapp@pharmchem.unifrankfurt.de

\section{Authors}

Martin Schröder - Institute of Pharmaceutical Chemistry and Structural Genomics Consortium, Buchmann Institute for Molecular Life Sciences (BMLS), Goethe-University Frankfurt, 60438 Frankfurt, Germany

Alex N. Bullock - Structural Genomics Consortium, Nuffield Department of Medicine, University of Oxford, Oxford OX3 7DQ, U.K.; 이이. orcid.org/0000-0001-6757-0436

Oleg Fedorov - Structural Genomics Consortium, Nuffield Department of Medicine, University of Oxford, Oxford OX3 $7 D Q, U . K$

Franz Bracher - Department of Pharmacy, Center for Drug Research, Ludwig-Maximilians University Munich, 81377 Munich, Germany; 이이.org/0000-0003-0009-8629

Complete contact information is available at: https://pubs.acs.org/10.1021/acs.jmedchem.0c00898

\section{Notes}

The authors declare no competing financial interest.

\section{ACKNOWLEDGMENTS}

The authors are grateful for support by the SGC, a registered charity (Number 1097737) that receives funds from AbbVie, Bayer Pharma AG, Boehringer Ingelheim, Canada Foundation for Innovation, Eshelman Institute for Innovation, Genome Canada, Janssen, Merck KGaA Darmstadt Germany, MSD, Novartis Pharma AG, Ontario Ministry of Economic Development and Innovation, Pfizer, São Paulo Research FoundationFAPESP, Takeda, Wellcome [Grant532 106169/ZZ14/Z], and EU/EFPIA/OICR/McGill/KTH/Diamond Innovative Medicines Initiative 2 Joint Undertaking [EUbOPEN grant no. 875510]. We are grateful to the DFG funded Collaborative Sonderforschungsbereich 1177 Autophagy (Grant SFB1177 to M.S., A.C., and S.K.) at Frankfurt University, as well as the German Translational Cancer Consortium. The authors thank staff at BESSY II, SLS and the Diamond Light Source beamline IO2 (proposal $\mathrm{mx} 442$ ) for their support during crystallographic X-ray diffraction testing and data collection. The data collection at SLS was supported by funding from the European Union's Horizon 2020 research and innovation program under Grant Agreement 730872, Project CALIPSOplus.

\section{ABBREVIATIONS USED}

CLK, Cdc2-like kinase; PIM, proviral insertion in murine kinase; ACVR1, activin receptor type I; DAPK, deathassociated protein kinase; DYRK, dual specificity tyrosinephosphorylation-regulated kinases; DRAK, DAP kinase-related apoptosis-inducing protein kinase; CK, casein kinase; RET, proto-oncogene tyrosine-protein kinase receptor Ret; CDK2, cyclin-dependent kinase 2; DFG motif, tripeptide Asp-Phe-Gly motif; VIAK motif, valine-isoleucine-alanine-lysine motif

\section{REFERENCES}

(1) Manning, G.; Whyte, D. B.; Martinez, R.; Hunter, T.; Sudarsanam, S. The protein kinase complement of the human genome. Science 2002, 298 (5600), 1912-1934.

(2) Manning, G.; Plowman, G. D.; Hunter, T.; Sudarsanam, S. Evolution of protein kinase signaling from yeast to man. Trends Biochem. Sci. 2002, 27 (10), 514-520.

(3) Roskoski, R., Jr. Properties of FDA-approved small molecule protein kinase inhibitors: a 2020 update. Pharmacol. Res. 2020, 152, 104609.

(4) Rask-Andersen, M.; Masuram, S.; Schioth, H. B. The druggable genome: evaluation of drug targets in clinical trials suggests major shifts in molecular class and indication. Annu. Rev. Pharmacol. Toxicol. 2014, 54, 9-26.

(5) Muller, S.; Chaikuad, A.; Gray, N. S.; Knapp, S. The ins and outs of selective kinase inhibitor development. Nat. Chem. Biol. 2015, 11 (11), 818-821.

(6) Lu, X.; Smaill, J. B.; Ding, K. New promise and opportunities for allosteric kinase inhibitors. Angew. Chem., Int. Ed. 2020, 59, 13764.

(7) Nagar, B.; Bornmann, W. G.; Pellicena, P.; Schindler, T.; Veach, D. R.; Miller, W. T.; Clarkson, B.; Kuriyan, J. Crystal structures of the kinase domain of c-ABL in complex with the small molecule inhibitors PD173955 and imatinib (STI-571). Cancer Res. 2002, 62 (15), 42364243.

(8) Zhao, Z.; Wu, H.; Wang, L.; Liu, Y.; Knapp, S.; Liu, Q.; Gray, N. $\mathrm{S}$. Exploration of type II binding mode: a privileged approach for kinase inhibitor focused drug discovery? ACS Chem. Biol. 2014, 9 (6), $1230-1241$.

(9) Chaikuad, A.; Tacconi, E. M. C.; Zimmer, J.; Liang, Y.; Gray, N. S.; Tarsounas, M.; Knapp, S. A unique inhibitor binding site in ERK1/ 2 is associated with slow binding kinetics. Nat. Chem. Biol. 2014, 10 (10), 853-860.

(10) Koeberle, S. C.; Romir, J.; Fischer, S.; Koeberle, A.; Schattel, V.; Albrecht, W.; Grutter, C.; Werz, O.; Rauh, D.; Stehle, T.; Laufer, S. A. Skepinone-L is a selective p38 mitogen-activated protein kinase inhibitor. Nat. Chem. Biol. 2012, 8 (2), 141-143.

(11) Fitzgerald, C. E.; Patel, S. B.; Becker, J. W.; Cameron, P. M.; Zaller, D.; Pikounis, V. B.; O'Keefe, S. J.; Scapin, G. Structural basis for p38alpha MAP kinase quinazolinone and pyridol-pyrimidine inhibitor specificity. Nat. Struct. Mol. Biol. 2003, 10 (9), 764-769.

(12) Wentsch, H. K.; Walter, N. M.; Buhrmann, M.; MayerWrangowski, S.; Rauh, D.; Zaman, G. J. R.; Willemsen-Seegers, N.; Buijsman, R. C.; Henning, M.; Dauch, D.; Zender, L.; Laufer, S. Optimized target residence time: type I1/2 inhibitors for p38alpha MAP kinase with improved binding kinetics through direct interaction with the R-spine. Angew. Chem., Int. Ed. 2017, 56 (19), 5363-5367.

(13) Gangadhara, G.; Dahl, G.; Bohnacker, T.; Rae, R.; Gunnarsson, J.; Blaho, S.; Oster, L.; Lindmark, H.; Karabelas, K.; Pemberton, N.; Tyrchan, C.; Mogemark, M.; Wymann, M. P.; Williams, R. L.; Perry, M. W. D.; Papavoine, T.; Petersen, J. A class of highly selective inhibitors bind to an active state of PI3Kgamma. Nat. Chem. Biol. 2019, 15 (4), 348-357.

(14) Chaikuad, A.; Koch, P.; Laufer, S. A.; Knapp, S. The cysteinome of protein kinases as a target in drug development. Angew. Chem., Int. Ed. 2018, 57 (16), 4372-4385. 
(15) Zuccotto, F.; Ardini, E.; Casale, E.; Angiolini, M. Through the "gatekeeper door": exploiting the active kinase conformation. J. Med. Chem. 2010, 53 (7), 2681-2694.

(16) Mondal, J.; Tiwary, P.; Berne, B. J. How a kinase inhibitor withstands gatekeeper residue mutations. J. Am. Chem. Soc. 2016, 138 (13), 4608-4615.

(17) Blencke, S.; Zech, B.; Engkvist, O.; Greff, Z.; Orfi, L.; Horvath, Z.; Keri, G.; Ullrich, A.; Daub, H. Characterization of a conserved structural determinant controlling protein kinase sensitivity to selective inhibitors. Chem. Biol. 2004, 11 (5), 691-701.

(18) Hari, S. B.; Merritt, E. A.; Maly, D. J. Sequence determinants of a specific inactive protein kinase conformation. Chem. Biol. 2013, 20 (6), 806-815.

(19) Yun, C. H.; Mengwasser, K. E.; Toms, A. V.; Woo, M. S.; Greulich, H.; Wong, K. K.; Meyerson, M.; Eck, M. J. The T790M mutation in EGFR kinase causes drug resistance by increasing the affinity for ATP. Proc. Natl. Acad. Sci. U. S. A. 2008, 105 (6), 20702075.

(20) Mian, A. A.; Schull, M.; Zhao, Z.; Oancea, C.; Hundertmark, A.; Beissert, T.; Ottmann, O. G.; Ruthardt, M. The gatekeeper mutation T315I confers resistance against small molecules by increasing or restoring the ABL-kinase activity accompanied by aberrant transphosphorylation of endogenous BCR, even in loss-offunction mutants of BCR/ABL. Leukemia 2009, 23 (9), 1614-1621.

(21) Sohl, C. D.; Ryan, M. R.; Luo, B.; Frey, K. M.; Anderson, K. S. Illuminating the molecular mechanisms of tyrosine kinase inhibitor resistance for the FGFR1 gatekeeper mutation: the achilles' heel of targeted therapy. ACS Chem. Biol. 2015, 10 (5), 1319-1329.

(22) Pogacic, V.; Bullock, A. N.; Fedorov, O.; Filippakopoulos, P.; Gasser, C.; Biondi, A.; Meyer-Monard, S.; Knapp, S.; Schwaller, J. Structural analysis identifies imidazo[1,2-b]pyridazines as PIM kinase inhibitors with in vitro antileukemic activity. Cancer Res. 2007, 67 (14), 6916-6924.

(23) Muraki, M.; Ohkawara, B.; Hosoya, T.; Onogi, H.; Koizumi, J.; Koizumi, T.; Sumi, K.; Yomoda, J.; Murray, M. V.; Kimura, H.; Furuichi, K.; Shibuya, H.; Krainer, A. R.; Suzuki, M.; Hagiwara, M. Manipulation of alternative splicing by a newly developed inhibitor of CLKs. J. Biol. Chem. 2004, 279 (23), 24246-24254.

(24) Moret, N.; Clark, N. A.; Hafner, M.; Wang, Y.; Lounkine, E.; Medvedovic, M.; Wang, J.; Gray, N.; Jenkins, J.; Sorger, P. K. Cheminformatics tools for analyzing and designing optimized smallmolecule collections and libraries. Cell Chem. Biol. 2019, 26 (5), 765777.

(25) Huber, K.; Brault, L.; Fedorov, O.; Gasser, C.; Filippakopoulos, P.; Bullock, A. N.; Fabbro, D.; Trappe, J.; Schwaller, J.; Knapp, S.; Bracher, F. 7,8-dichloro-1-oxo-beta-carbolines as a versatile scaffold for the development of potent and selective kinase inhibitors with unusual binding modes. J. Med. Chem. 2012, 55 (1), 403-413.

(26) Pierce, A. C.; Jacobs, M.; Stuver-Moody, C. Docking study yields four novel inhibitors of the protooncogene PIM-1 kinase. J. Med. Chem. 2008, 51 (6), 1972-1975.

(27) Nemec, V.; Hylsova, M.; Maier, L.; Flegel, J.; Sievers, S.; Ziegler, S.; Schroder, M.; Berger, B. T.; Chaikuad, A.; Valcikova, B.; Uldrijan, S.; Drapela, S.; Soucek, K.; Waldmann, H.; Knapp, S.; Paruch, K. Furo[3,2-b]pyridine: a privileged scaffold for highly selective kinase inhibitors and effective modulators of the hedgehog pathway. Angew. Chem., Int. Ed. 2019, 58 (4), 1062-1066.

(28) Mott, B. T.; Tanega, C.; Shen, M.; Maloney, D. J.; Shinn, P.; Leister, W.; Marugan, J. J.; Inglese, J.; Austin, C. P.; Misteli, T.; Auld, D. S.; Thomas, C. J. Evaluation of substituted 6-arylquinazolin-4amines as potent and selective inhibitors of cdc2-like kinases (CLK). Bioorg. Med. Chem. Lett. 2009, 19 (23), 6700-6705.

(29) Cincinelli, R.; Cassinelli, G.; Dallavalle, S.; Lanzi, C.; Merlini, L.; Botta, M.; Tuccinardi, T.; Martinelli, A.; Penco, S.; Zunino, F. Synthesis, modeling, and RET protein kinase inhibitory activity of 3and 4-substituted beta-carbolin-1-ones. J. Med. Chem. 2008, 51 (24), $7777-7787$.

(30) Kim, M. K.; Min, J.; Choi, B. Y.; Lim, H.; Cho, Y. H.; Lee, C. H. Discovery of cyclin-dependent kinase inhibitor, CR229, using structurebased drug screening. J. Microbiol. Biotechnol. 2007, 17 (10), $1712-1716$.

(31) Scotti, M. M.; Swanson, M. S. RNA mis-splicing in disease. Nat. Rev. Genet. 2016, 17 (1), 19-32.

(32) Bullock, A. N.; Das, S.; Debreczeni, J. E.; Rellos, P.; Fedorov, O.; Niesen, F. H.; Guo, K.; Papagrigoriou, E.; Amos, A. L.; Cho, S.; Turk, B. E.; Ghosh, G.; Knapp, S. Kinase domain insertions define distinct roles of CLK kinases in SR protein phosphorylation. Structure 2009, 17 (3), 352-362.

(33) Robers, M. B.; Friedman-Ohana, R.; Huber, K.; Kilpatrick, L.; Vasta, J. D.; Berger, B. T.; Chaudhry, C.; Hill, S.; Muller, S.; Knapp, S.; Wood, K. V. Quantifying target occupancy of small molecules within living cells. Annu. Rev. Biochem. 2020, 89, 557-581.

(34) Vasta, J. D.; Corona, C. R.; Wilkinson, J.; Zimprich, C. A.; Hartnett, J. R.; Ingold, M. R.; Zimmerman, K.; Machleidt, T.; Kirkland, T. A.; Huwiler, K. G.; Ohana, R. F.; Slater, M.; Otto, P.; Cong, M.; Wells, C. I.; Berger, B. T.; Hanke, T.; Glas, C.; Ding, K.; Drewry, D. H.; Huber, K. V. M.; Willson, T. M.; Knapp, S.; Muller, S.; Meisenheimer, P. L.; Fan, F.; Wood, K. V.; Robers, M. B. Quantitative, wide-spectrum kinase profiling in live cells for assessing the effect of cellular ATP on target engagement. Cell Chem. Biol. 2018, 25 (2), 206-214.

(35) Shults, M. D.; Janes, K. A.; Lauffenburger, D. A.; Imperiali, B. A multiplexed homogeneous fluorescence-based assay for protein kinase activity in cell lysates. Nat. Methods 2005, 2 (4), 277-283.

(36) Shults, M. D.; Carrico-Moniz, D.; Imperiali, B. Optimal soxbased fluorescent chemosensor design for serine/threonine protein kinases. Anal. Biochem. 2006, 352 (2), 198-207.

(37) Fedorov, O.; Huber, K.; Eisenreich, A.; Filippakopoulos, P.; King, O.; Bullock, A. N.; Szklarczyk, D.; Jensen, L. J.; Fabbro, D.; Trappe, J.; Rauch, U.; Bracher, F.; Knapp, S. Specific CLK inhibitors from a novel chemotype for regulation of alternative splicing. Chem. Biol. 2011, 18 (1), 67-76.

(38) Elkins, J. M.; Fedele, V.; Szklarz, M.; Abdul Azeez, K. R.; Salah, E.; Mikolajczyk, J.; Romanov, S.; Sepetov, N.; Huang, X. P.; Roth, B. L.; Al Haj Zen, A.; Fourches, D.; Muratov, E.; Tropsha, A.; Morris, J.; Teicher, B. A.; Kunkel, M.; Polley, E.; Lackey, K. E.; Atkinson, F. L.; Overington, J. P.; Bamborough, P.; Muller, S.; Price, D. J.; Willson, T. M.; Drewry, D. H.; Knapp, S.; Zuercher, W. J. Comprehensive characterization of the published kinase inhibitor set. Nat. Biotechnol. 2016, 34 (1), 95-103.

(39) Drewry, D. H.; Willson, T. M.; Zuercher, W. J. Seeding collaborations to advance kinase science with the GSK published kinase inhibitor set (PKIS). Curr. Top. Med. Chem. 2014, 14 (3), 340-342.

(40) Kallen, J.; Bergsdorf, C.; Arnaud, B.; Bernhard, M.; Brichet, M.; Cobos-Correa, A.; Elhajouji, A.; Freuler, F.; Galimberti, I.; Guibourdenche, C.; Haenni, S.; Holzinger, S.; Hunziker, J.; Izaac, A.; Kaufmann, M.; Leder, L.; Martus, H. J.; von Matt, P.; Polyakov, V.; Roethlisberger, P.; Roma, G.; Stiefl, N.; Uteng, M.; Lerchner, A. Xray structures and feasibility assessment of CLK2 inhibitors for phelan-mcdermid syndrome. ChemMedChem 2018, 13 (18), 19972007.

(41) Funnell, T.; Tasaki, S.; Oloumi, A.; Araki, S.; Kong, E.; Yap, D.; Nakayama, Y.; Hughes, C. S.; Cheng, S. G.; Tozaki, H.; Iwatani, M.; Sasaki, S.; Ohashi, T.; Miyazaki, T.; Morishita, N.; Morishita, D.; Ogasawara-Shimizu, M.; Ohori, M.; Nakao, S.; Karashima, M.; Sano, M.; Murai, A.; Nomura, T.; Uchiyama, N.; Kawamoto, T.; Hara, R.; Nakanishi, O.; Shumansky, K.; Rosner, J.; Wan, A.; McKinney, S.; Morin, G. B.; Nakanishi, A.; Shah, S.; Toyoshiba, H.; Aparicio, S. CLK-dependent exon recognition and conjoined gene formation revealed with a novel small molecule inhibitor. Nat. Commun. 2017, 8 (1), 7 .

(42) Walter, A.; Chaikuad, A.; Helmer, R.; Loaec, N.; Preu, L.; Ott, I.; Knapp, S.; Meijer, L.; Kunick, C. Molecular structures of cdc2-like kinases in complex with a new inhibitor chemotype. PLoS One 2018, 13 (5), e0196761.

(43) Fruit, C.; Couly, F.; Bhansali, R.; Rammohan, M.; Lindberg, M. F.; Crispino, J. D.; Meijer, L.; Besson, T. Biological characterization of 
8-cyclopropyl-2-(pyridin-3-yl)thiazolo[5,4-f]quinazolin-9(8H)-one, a promising inhibitor of DYRK1A. Pharmaceuticals 2019, 12 (4), 185. (44) Chaikuad, A.; Diharce, J.; Schroder, M.; Foucourt, A.; Leblond, B.; Casagrande, A. S.; Desire, L.; Bonnet, P.; Knapp, S.; Besson, T. An unusual binding model of the methyl 9-anilinothiazolo[5,4-f] quinazoline-2-carbimidates (EHT 1610 and EHT 5372) confers high selectivity for dual-specificity tyrosine phosphorylation-regulated kinases. J. Med. Chem. 2016, 59 (22), 10315-10321.

(45) Hanke, T.; Wong, J. F.; Berger, B. T.; Abdi, I.; Berger, L. M.; Tesch, R.; Tredup, C.; Bullock, A. N.; Muller, S.; Knapp, S. A highly selective chemical probe for activin receptor-like kinases ALK4 and ALK5. ACS Chem. Biol. 2020, 15 (4), 862-870.

(46) Sun, Q. Z.; Lin, G. F.; Li, L. L.; Jin, X. T.; Huang, L. Y.; Zhang, G.; Yang, W.; Chen, K.; Xiang, R.; Chen, C.; Wei, Y. Q.; Lu, G. W.; Yang, S. Y. Discovery of potent and selective inhibitors of cdc2-like kinase 1 (CLK1) as a new class of autophagy inducers. J. Med. Chem. 2017, 60 (14), 6337-6352.

(47) Oshima, T.; Niwa, Y.; Kuwata, K.; Srivastava, A.; Hyoda, T.; Tsuchiya, Y.; Kumagai, M.; Tsuyuguchi, M.; Tamaru, T.; Sugiyama, A.; Ono, N.; Zolboot, N.; Aikawa, Y.; Oishi, S.; Nonami, A.; Arai, F.; Hagihara, S.; Yamaguchi, J.; Tama, F.; Kunisaki, Y.; Yagita, K.; Ikeda, M.; Kinoshita, T.; Kay, S. A.; Itami, K.; Hirota, T. Cell-based screen identifies a new potent and highly selective CK2 inhibitor for modulation of circadian rhythms and cancer cell growth. Sci. Adv. 2019, 5 (1), eaau9060.

(48) Carlson, D. A.; Singer, M. R.; Sutherland, C.; Redondo, C.; Alexander, L. T.; Hughes, P. F.; Knapp, S.; Gurley, S. B.; Sparks, M. A.; MacDonald, J. A.; Haystead, T. A. J. Targeting PIM kinases and DAPK3 to control hypertension. Cell Chem. Biol. 2018, 25 (10), 1195-1207.

(49) Kooistra, A. J.; Kanev, G. K.; van Linden, O. P.; Leurs, R.; de Esch, I. J.; de Graaf, C. KLIFS: a structural kinase-ligand interaction database. Nucleic Acids Res. 2016, 44 (D1), D365-371.

(50) Battye, T. G.; Kontogiannis, L.; Johnson, O.; Powell, H. R.; Leslie, A. G. iMOSFLM: a new graphical interface for diffractionimage processing with MOSFLM. Acta Crystallogr., Sect. D: Biol. Crystallogr. 2011, 67 (4), 271-281.

(51) Kabsch, W. XDS. Acta Crystallogr., Sect. D: Biol. Crystallogr. 2010, 66 (2), 125-132.

(52) Evans, P. R.; Murshudov, G. N. How good are my data and what is the resolution? Acta Crystallogr., Sect. D: Biol. Crystallogr. 2013, 69 (7), 1204-1214.

(53) McCoy, A. J.; Grosse-Kunstleve, R. W.; Adams, P. D.; Winn, M. D.; Storoni, L. C.; Read, R. J. Phaser crystallographic software. J. Appl. Crystallogr. 2007, 40 (4), 658-674.

(54) Chaikuad, A.; Alfano, I.; Kerr, G.; Sanvitale, C. E.; Boergermann, J. H.; Triffitt, J. T.; von Delft, F.; Knapp, S.; Knaus, P.; Bullock, A. N. Structure of the bone morphogenetic protein receptor ALK2 and implications for fibrodysplasia ossificans progressiva. J. Biol. Chem. 2012, 287 (44), 36990-36998.

(55) Emsley, P.; Lohkamp, B.; Scott, W. G.; Cowtan, K. Features and development of coot. Acta Crystallogr., Sect. D: Biol. Crystallogr. 2010, 66 (4), 486-501.

(56) Murshudov, G. N.; Vagin, A. A.; Dodson, E. J. Refinement of macromolecular structures by the maximum-likelihood method. Acta Crystallogr., Sect. D: Biol. Crystallogr. 1997, 53 (3), 240-255.

(57) Chen, V. B.; Arendall, W. B., 3rd; Headd, J. J.; Keedy, D. A.; Immormino, R. M.; Kapral, G. J.; Murray, L. W.; Richardson, J. S.; Richardson, D. C. MolProbity: all-atom structure validation for macromolecular crystallography. Acta Crystallogr., Sect. D: Biol. Crystallogr. 2010, 66 (1), 12-21.

(58) Tian, W.; Chen, C.; Lei, X.; Zhao, J.; Liang, J. CASTp 3.0: computed atlas of surface topography of proteins. Nucleic Acids Res. 2018, 46 (W1), W363-W367.

(59) Madeira, F.; Park, Y. M.; Lee, J.; Buso, N.; Gur, T.; Madhusoodanan, N.; Basutkar, P.; Tivey, A. R. N.; Potter, S. C.; Finn, R. D.; Lopez, R. The EMBL-EBI search and sequence analysis tools APIs in 2019. Nucleic Acids Res. 2019, 47 (W1), W636-W641.
(60) Thomsen, M. C.; Nielsen, M. Seq2Logo: a method for construction and visualization of amino acid binding motifs and sequence profiles including sequence weighting, pseudo counts and two-sided representation of amino acid enrichment and depletion. Nucleic Acids Res. 2012, 40, W281-W287 (Web Server issue).

(61) Fedorov, O.; Niesen, F. H.; Knapp, S. Kinase inhibitor selectivity profiling using differential scanning fluorimetry. Methods Mol. Biol. 2012, 795, 109-118.

(62) Robers, M. B.; Vasta, J. D.; Corona, C. R.; Ohana, R. F.; Hurst, R.; Jhala, M. A.; Comess, K. M.; Wood, K. V. Quantitative, real-time measurements of intracellular target engagement using energy transfer. Methods Mol. Biol. 2019, 1888, 45-71. 